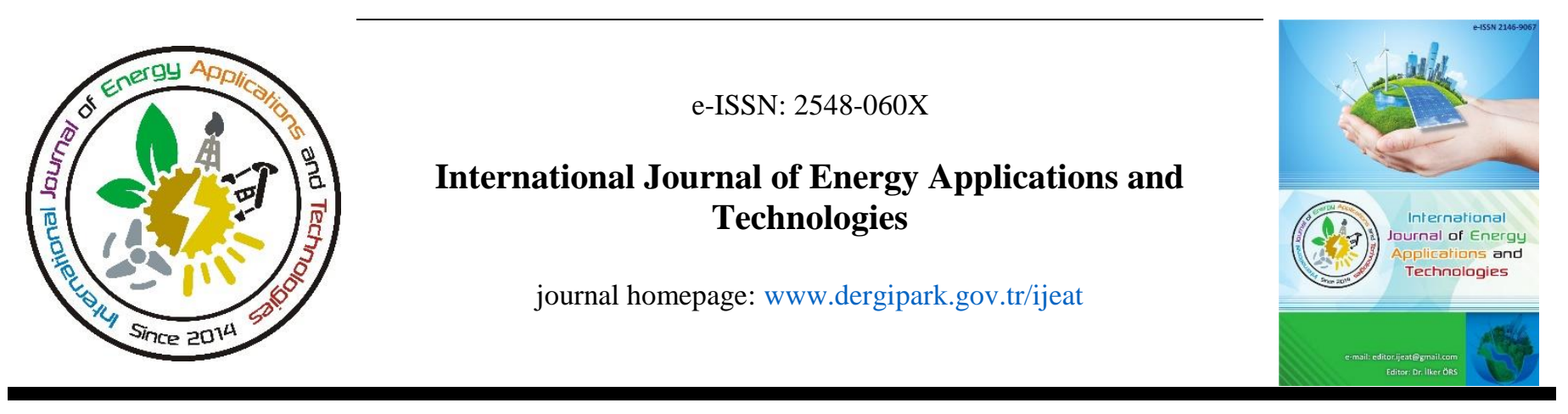

Original Research Article

\title{
Proposal of an analog voltmeter PCB's design layout based on DFMEA methodology for failure reduction
}

\author{
Daniel Katz Bonello *, Yuzo Iano, Umberto Bonello Neto \\ School of Electrical and Computer Engineering, University of Campinas, Campinas, BRAZIL
}

ARTICLE INFO
* Corresponding author
d208944@ g.unicamp.br
Received March 1, 2018
Accepted March 30, 2018
Published by Editorial Board
Members of IJEAT
C This article is distributed by
Turk Journal Park System under
the CC 4.0 terms and conditions.

\begin{abstract}
With the constant demand of automotive industries for embedded electronic devices in order to employ them in vehicles that needs constant monitoring and management of their energy systems, analog voltmeters are used in this kind of application by their measurement efficiency and driver's assistance. This electronic device is often used for variable's controlling in fields where requires total measurement precision, for example: automotive embedded systems, process control, electrical machine testing, electronic diagnosis and so on. Therefore, the main objective of this work is to apply the physical and mathematical concepts of electronics to an automotive embedded system which requires the design of two PCB's utilizing DFMEA methodology. The current work was designed to the development of an analog voltmeter PCB's design layout based on DFMEA (Design Failure Mode and Effects Analysis) methodology, to avoid potential failures during design conception. The confection process of those PCB's layouts begins with the analysis of two original circuits in AutoCAD, where the main problem observed was the alterations to be done in the circuits because the layer's distribution scenario. This problem was solved through SMT components re-adjustment applying DFMEA methodology. In the application of this methodology, the percentage of failures was about to $61 \%$ to the first circuit and 38\% to the second circuit. This result appoints that the application of DFMEA in PCB's design layout is highly efficient to detect, identify and classify the risk and severity of potential failures during the project development.
\end{abstract}

\section{Introduction}

Voltmeters are instruments that are designed with the finality to measure electric tensions. We can also build voltmeters from galvanometers. Even that a current "i" across a galvanometer, your extremities are submitted to a tension given by " $r$. $i$ ". As the ammeter case, there is also a maximum tension supported by galvanometer that is given by " $\mathrm{Vg}=\mathrm{r}$. ig" [1].

If we desire to build a voltmeter to measure a tension higher than "Vg" of the available galvanometer, we must associate him a resistor in series "Rm" (multiplier resistor). To select a suitable "Rm" value to the acquisition of a background tension with "Vf" scale we must consider that, in this case, the current that across the galvanometer (and also through "Rm") is "ig" [1]. From circuit given by Figure 1, we can see that "Vf=Vg $+V m$ ". By the equations "Vg=r. ig" and "Vm $=\mathrm{Rm}$. ig", we have also the final diagram in Figure 1 [1]. Now, if we want to build a single voltmeter for various scale backgrounds, we must use the Equation (4) to calculate all proper "Rm" which can be selected by an external-key named " $\mathrm{K}$ ". In the calibration of scales (connected to a pointer) of a voltmeter we can also use default currents. Although, the 
values indicated in the scale are not the value of currents, but comes from the multiplication with total electrical resistance "R" of voltmeter, with "R $=\mathrm{Rm}+\mathrm{r}$ ", for each background scale. We also must observe that a voltmeter (in continuous voltage measurement) also has an intern polarity and resistance. The voltmeter must be connected in parallel with the point of circuit that is desired to know the tension values [1]. In the case of this work, with the terminals of batteries connected in series.

This analogy voltmeter was developed, using DFMEA methodology, to manage the work of batteries connected in series of $24 \mathrm{v}$. This technology allows the reading of signal from alternator and manages these informations, correcting loadings distribution failures, and sending in a correct way the ideal amperage of each battery [2]. This electronic device increases the battery and alternator lifetime, and potentiate the action of starter motor through equilibrium of amperages, avoiding the overload between vehicle batteries [2]. In addition, the analogy voltmeter described in this paper, also ceases with superficial reading of multimeter - a reading that measures just only the medium state of batteries and not one by one, individually - that is: this device provides a exactly voltage of each battery and allows your correct work [2]. Therefore, must be applied in any equipment or vehicle that has batteries connected in series of $24 \mathrm{v}$.

In reality, what defines the ideal model of an analogy voltmeter to be applied in machines or vehicles is the summary of consumptions. In the other words, a number of electronic accessories installed in a vehicle or machine is what defines the model to be utilized in the respective application, who can be based on 10, 20 or 50 amperes [2].

Actually the model YK50 is the most complete device. With the installation of this product, the costs of a determined vehicle shipping can be reduced, increasing the battery and alternator lifetime. Moreover, problems in the electrical system can be avoided, up from the igual loading process of batteries, and in this way the peaks of high tension can be stabilized, controlling the consumption of peripheral components connected to the battery, and enabling the fuel economy. This analogy voltmeter includes a display with two voltmeters that are fixed on the vehicles or machines panel [2].

In concern with PCB's layout design development, the Design Failure Mode and Effects Analysis (DFMEA) is, fundamentally, a structured approach used to prevent problems in respect of product project, your causes and effects [3]. The DFMEA methodology involves all product structure items, even the minor parts as subsystems or components, identifying the potential failure mode and causes started in each product part, determining the actual controls (or solutions) to the failure causes, forwarded by failure effects for product assembly and to the final customers [4]. The risks of failures are estimated.

As DFMEA is concerned to the product design activities, we must establish in the initial stages of product project, an efficient and wide quality system. Thus, DFMEA is an appropriate tool for this finality [5]. In this work, the DFMEA strategies used to identify, classify and evaluate the risks of PCB's design failures begins with the project of two electrical circuits diagrams in AutoCAD and goes on until the final phase, which requires product functionality tests using Proteus software.

The first step of development, as cited before, begins with the analysis of the project that contains the whole structure of analogy voltmeter electrical circuits, but these circuits have critical errors regarding to the layer's distribution. The DFMEA steps used to the development of circuits are: a) drawing historical; b) ECR (Engineering Change Request); c) analysis of two circuits SMT components; d) addressing of SMT components; e) analysis of critical characteristics to both circuits; f) components criteria failure quantitative analysis; g) engineering approbation; $h$ ) restructuration and optimization of circuits layers; i) final design of two electrical circuits after restructuration; $\mathrm{j}$ ) addressing of SMT components after restructuration; k) final circuits layout to etching process; 1) final product functionality tests.

The results appoint that the percentage of potential failures was about to $61 \%$ to the first circuit and $38 \%$ to the second circuit in the step of quantitative analysis. The results indicates that the application of DFMEA is efficient to reduce potential failures during the project development.

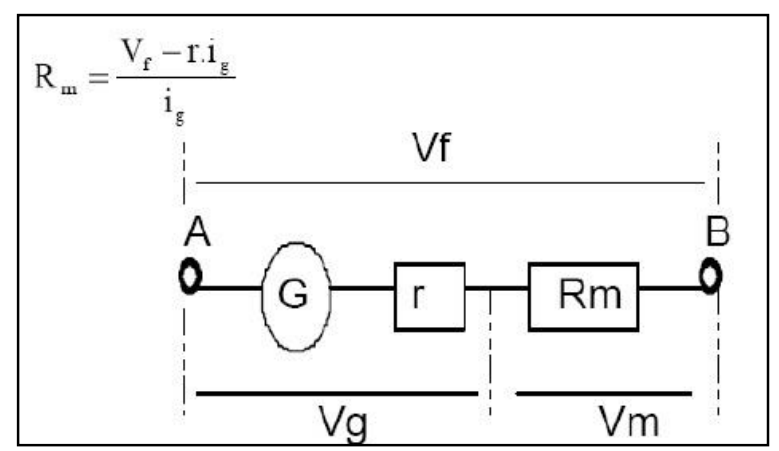

Figure 1. Scheme of a voltmeter

$$
\begin{aligned}
& \mathrm{Vg}=\mathrm{R} . \mathrm{ig} \\
& \mathrm{Vf}=\mathrm{Vg}+\mathrm{Vm} \\
& \mathrm{Vm}=\mathrm{Rm} \cdot \mathrm{ig} \\
& \mathrm{Rm}=\frac{\mathrm{Vf}-\mathrm{r} \cdot \mathrm{ig}}{\mathrm{ig}}
\end{aligned}
$$


Regarding to the analog voltmeter functionality tests, the working principle is on the total loading analysis between 27.8 and $28.0 \mathrm{v}$. After the first battery reaches a loading value of $13.8 \mathrm{v}$ the voltmeter will start to work, managing and loading the two batteries connected in series, until the equalization around $13.9 \mathrm{v}$ for each battery. After this equalization and not having excessive consumption the process is suspended up to a new loading necessity.

The objectives of DFMEA are properly described, in a widely way, by QS9000 manual in the third edition [6]. And the details of this methodology are introduced by Ford manual [7].

\section{Method}

This section will describe the development process of two PCB circuit layout design using DFMEA methodology.

In the first subtopic of this section, the integrated circuit LM3914 will be analysed: this step will have as a main target take a brief about the working principle of LM3914, which the main function aggregated in the second circuit of analogy voltmeter is monitoring the linear signal of tension, showing in the vehicle or machine display panel the state of batteries. Also will be exposed the internal architecture of LM3914, and indicated the main pins to be utilized in the second circuit of analogy voltmeter.

Now in the second subtopic, will be exposed the most relevant concepts of SMT components, such as resistors codes and re-work techniques, both concepts will be described within a shortly introduction.

In the subsequent subtopics, the DFMA steps described in Introduction will be exposed in details to show how the results are obtained using this methodology.

This current section uses technical manuals, datasheets, technical books, lectures notes and materials available on web to verify theorically the procedures used during the confection of analog voltmeter. Thus, from these steps, the report of PCB's development using DFMEA methodology can be exposed in a completely way, as shown in the subtopics above.

\subsection{Working principle of integrated circuit LM3914}

The integrated circuit LM3914 is a linear tension indicator, which has as main application made the monitoring of linear signals applied in the IC input. Your working principle is very simple, while the signal applied in the input is increased, your correspondent led's are started on a scale from 1 up to 10. The leds can be set in the "mobile point" or "mobile bar" mode [9]. In the case of this work, the "mobile bar" pattern was utilized. Figure 2 shows this configuration.

The nominal reference tension of output it's about $1.25 \mathrm{v}$, and this value implies a division under the resistive mesh, resulting in $125 \mathrm{mv}$ for each resistor. In this mode, for each
$125 \mathrm{mv}$ increased in the input a new comparator will have your output commutated (from the top to the bottom) and a new led will be turned on. The Figure 3 shows this process.

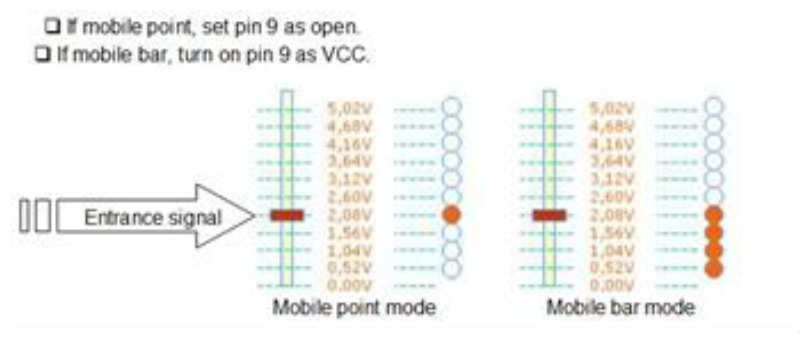

Figure 2. Mobile point or mobile bar monitoring

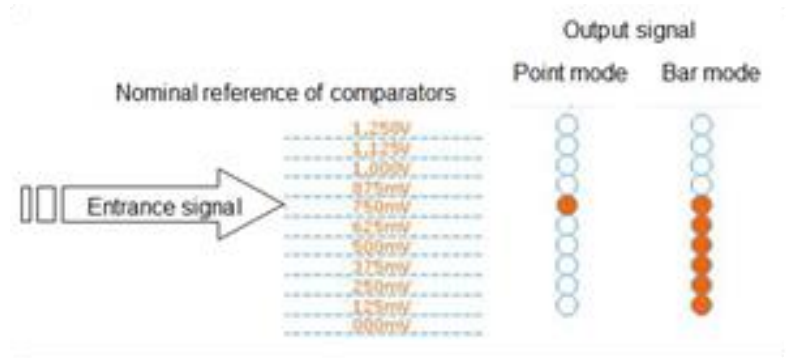

Figure 3. Reference tension

As illustrates Figure 4, the reference adjusted by project designer will be divided under resistive mesh, having in this way a value of $0.52 \mathrm{v}$ under each resistor. An important characteristic of LM3914 is: when the comparator reference is reached, your output commutes from the higher logical level to the lower logical level, setting on the correspondent led's.

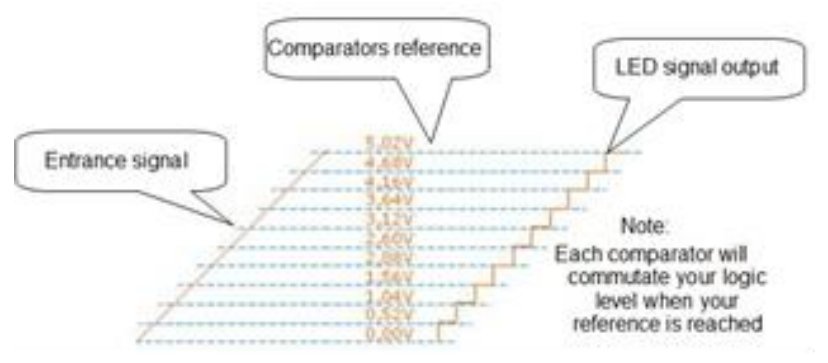

Figure 4. Reference divided under resistive line

A simplified block diagram shows us a general idea about how works the integrated circuit LM3914. Internally, this IC has 10 comparators, each one with a respective reference, designed by the resistive mash. Your outputs commutates from a higher logical level to the lower logic level, hence your references are reached [9].

In respect of the main pins of IC LM3914 to be used in the circuit layout design of analog voltmeter, stands out the signal input port (pin 5) and the reference output port (pin 7), as indicated in the Figure 6, further the led's output ports. In the second electrical circuit of analog voltmeter, where is employed the integrated circuit LM3914, the pin 5 of this IC (signal input port) is connected to the pin 2 (GND), through a resistor. This connection is responsible from the higher 
level to the lower level commutation to start of a reference reached by comparators of IC LM3914.

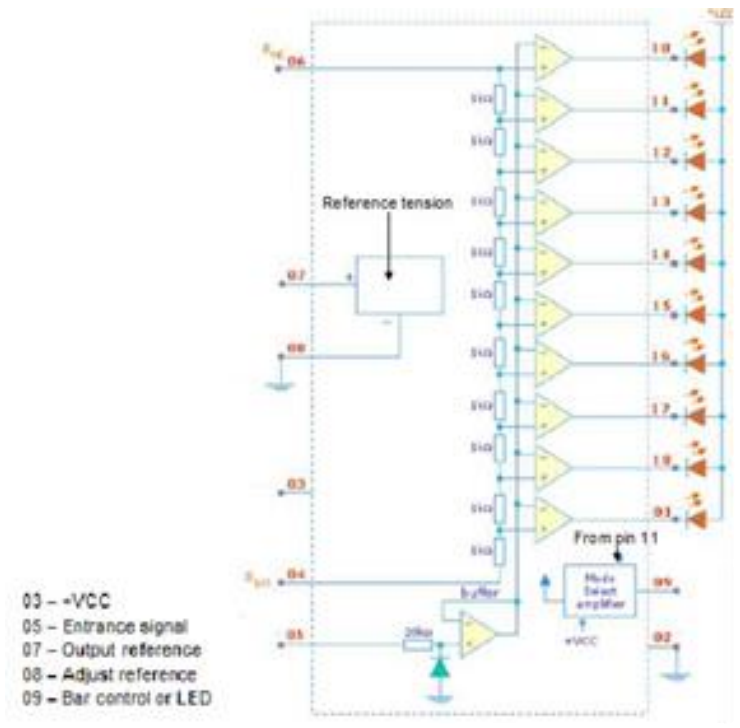

Figure 5. Internal architecture of IC LM3914

Now the pin 7 (reference output port) is connected to the pin 6 (higher divisor) to posteriorly be connected to the lower divisor (pin 4). In the end, through pin 4, the output reference will be associated with the feeding circuit (GND) to auxiliary the mentioned commutation.

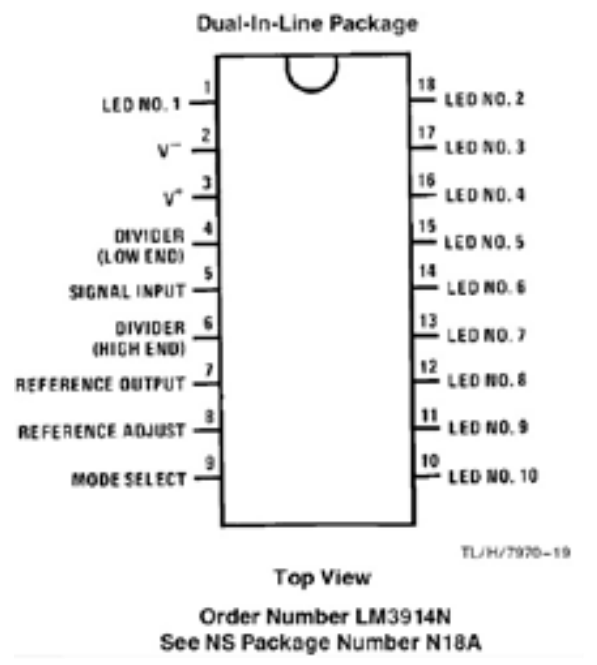

Figure 6. Datasheet of LM3914

\subsection{Main concepts about SMT components}

The components of surface mount technology (SMT) are present in the mostly consumption devices: industrial or modern embedded systems. Among the difficulties that maintenance and repair professionals found is the codes reading that indicates the values of this components [10]. In the subtopics below, will be described concepts of resistors codes reading methodologies and SMT rework techniques. The SMT resistors have a code with 3 or 4 digits in your mostly common configuration, as described in the Figure 7.

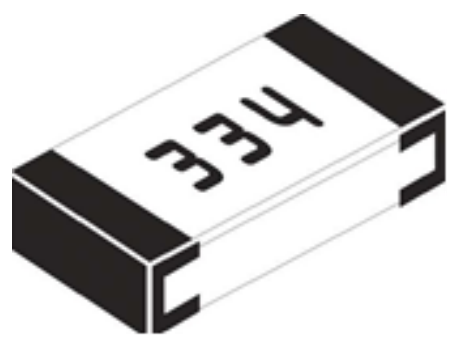

Figure 7. Example of SMT code

In this code, the two first numbers indicates the two first digits of resistance. In this case, $33 \Omega$. The third digit means the multiplication factor, or the number of zeros that must to be added. In this case, 0000 zeros. Thus, we have for this resistor a value of $330 \mathrm{~K} \Omega$.

For resistances lower than $10 \Omega$ we can use the letter " $R$ " to represents the unity of "Ohm $-\Omega$ ", or to replace the decimal point. So, we can represent $10 \mathrm{R}$ for $10 \Omega$ or $4 \mathrm{R} 7$ for $4.7 \Omega$. In some cases, with resistors in the range of $10 \Omega$ to $99 \Omega$, we can have the use of just only two digits to avoid confusions. For example: 33 or 56 to indicate $33 \Omega$ or $56 \Omega$.

Also exists cases in that "K" (kilo) and "M" (mega) are used instead of decimal point. However, to the most restrict tolerances, there are many other types of codes. Examples of: SMT codes to restrict tolerances, size and characteristics to SMT resistors, and tolerance \& temperature coefficient of SMT components as shown the Table 1, Table 2 and Table 3 respectively.

Table 1. SMT codes to restrict tolerances

\begin{tabular}{ll}
\hline 3-digit codes & 4-digit codes \\
\hline 220 is $22 \Omega$, and not $220 \Omega$ & 1000 is $100 \Omega$, and not $1 \mathrm{~K} \Omega$ \\
331 is $330 \Omega$ & 4992 is $49 \mathrm{~K} 9 \Omega$ \\
563 is $56 \mathrm{~K} \Omega$ & 5572 is $55 \mathrm{~K} 7 \Omega$ \\
105 is $1 \mathrm{M} \Omega$ & 1623 is $162 \mathrm{~K} \Omega$ \\
$6 \mathrm{R} 8$ is $6.8 \Omega$ & $0 \mathrm{R} 56$ or $\mathrm{R} 56$ is $1.56 \Omega$ \\
\hline
\end{tabular}

Table 2. SMT size and characteristics

\begin{tabular}{ll}
\hline SMT Model & Dissipation (Watts) \\
\hline 0402 & $1 / 16$ \\
0603 & $1 / 10$ \\
0805 & $1 / 8$ \\
1206 & $1 / 4$ \\
1210 & $1 / 3$ \\
2010 & $3 / 4$ \\
2512 & 1 \\
3616 & 2 \\
4022 & 3 \\
\hline
\end{tabular}

Table 3. SMT tolerance and temperature coefficient

\begin{tabular}{ll}
\hline Tolerance (\%) & Temperature coef. $(\mathbf{R})$ \\
\hline 0,1 & 25 \\
0,5 & 50 \\
1 & 100 \\
\hline
\end{tabular}




\subsubsection{SMT rework techniques}

The SMT rework, as called the process of extraction and replacement of components in a board, when realized with SMT components, requires special techniques and devices [11]. As this kind of operation must to be known by all professionals of electronics, in this part of this subtopic will be provided some important informations to the maintenance of devices that employs SMT components.

Some time ago, the wrappings of electronic components have just the function of protect them against the external environment and serve as sustentation material for a mounting. There was no preoccupation about the component size, and then, the wrappings were fit enough to be easily manipulated by a mounting or reparation professional. With the advance of technologies, everything was changed. The components that before would be easily manipulated, started to have dimensions so reduced, that the manipulation in a traditional way for a human professional become difficult [11].

Therefore, the main SMT rework techniques are described below:

1. Welding: to SMT components from groups 0805, 1206, SOT-23 and others, such as resistors, capacitors, and diodes, we must welding "pin per pin", placing them with a clip in mode of align terminals with welding points. After, using a soldering iron, we must proceed in a traditional way as indicates Figure 8.

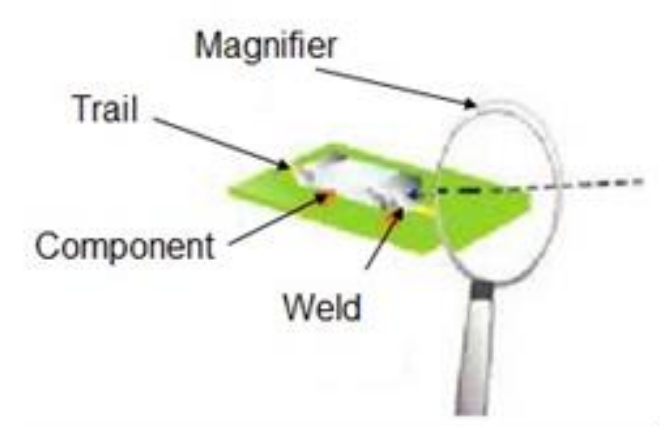

Figure 8. SMT component welding

The remotion of remained connections between pins can be done with a desoldering nib, or even with a tiny nib passing her between terminals. An important aspect to be considered in this procedure, is that weld can be "lift up" until the higher height of pinning, mixing around and creating connections which are most difficult to be removed.

2. Desoldering: there are two finalities to the desoldering process of SMT components in a printed circuit board. One of them is the recovery components and other is the components removing for substitution, because components are burned. It's obvious that in the first case we must employ a non-destructive process of components removing or extraction. Now in the second case there is not this problem, because component will not be more used.
The most indicated process is who that is obtained with a welding station that has the necessary resources to the components extraction through your weld fusion. However, there is a cheaper technique, because do not requires the employment of special components, and is specially indicated to the integrated circuits remotion, as Figure 9 shows.

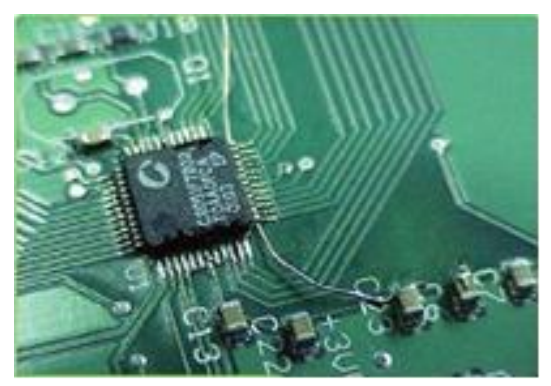

Figure 9. Wire wrap technique

In the usage of this technique, we pass a "wire wrape" wiring under component terminals in the trail which we desires have a desoldering. Then, passing now the welder under pins in a way to fuse the weld, it's possible pull the wring up in a mode to release terminals.

The process must be done with delicacy, must the welder be passed under terminals until all them be released.

\subsection{First DFMEA step: Analysis of pre-defined circuits}

During the work of circuits development, the central focus was based on the confection of two electrical diagrams of analog voltmeter using AutoCAD, as described in the Introduction of this paper. The first step of development, using DFMEA methodology, is based on the analysis of the project developed by supplier, which contains the whole structure of analog voltmeter electrical circuits, but have several errors regarding to the circuit layer's distribution. The suppliers of parts/devices, of automotive sector, follow Quality Standards to assure that products fabrication can be done in a correct way, avoiding disorders. For that purpose, the ISO/TS standards also were used during analog voltmeter circuits development.

Before project errors analysis based on DFMEA methodology, it's important expose that the procedures of APQP - PPAP were followed to develop a Control Plan process. The PPAP procedure is defined by an own manual and published by AIAG (Automotive Industry Action Group), which serves as the base to the Control Plan creation. Therefore, this developed work using the DFMEA method, it's conforming to the PPAP steps for results obtention. The next Figure 10 frame indicates the DFMEA steps used during analog voltmeter circuits development.

The next subtopics will describes the followed steps of DFMEA procedures, to the pre-defined electric circuits analysis effect. 


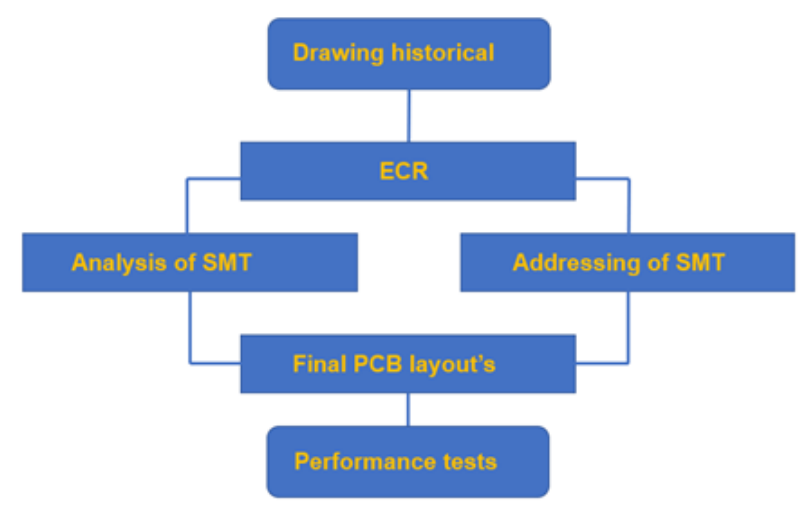

Figure 10. Flowchart of methodology process

\subsubsection{Drawing historical}

The drawing historical consists of a recorded drawing copy of the project development. The project of this work will be the changes to be realized in the layers of two electrical circuits: named as "G1" and "G2", respectively.

The Figure 11 and Figure 12 below represents the recorded copy in electronic mode (.dwg), which constitutes the experimental pre-defined assembly of this work, developed in AutoCAD 2010.

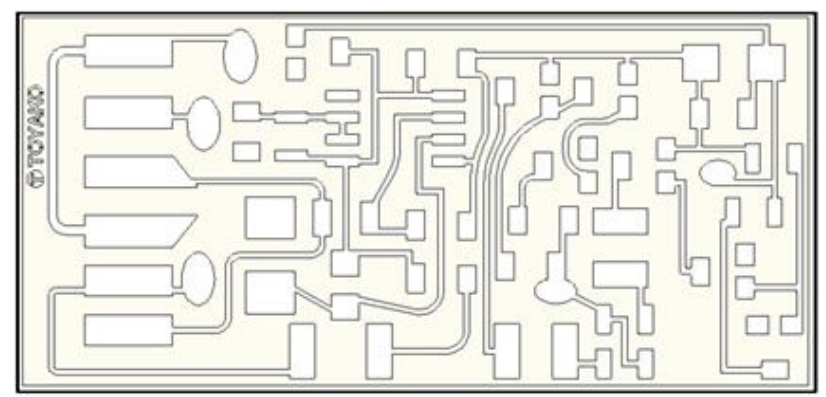

Figure 11. Electrical circuit "G1"

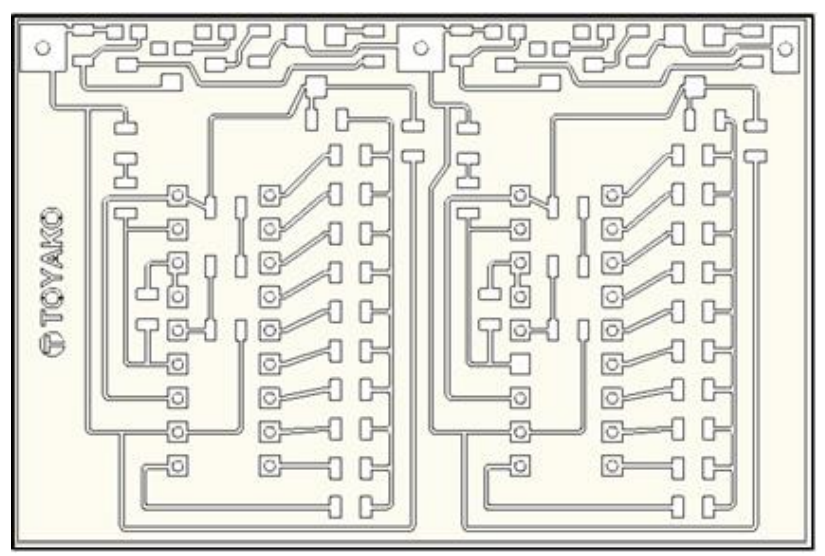

Figure 12. Electrical circuit "G2"

\subsubsection{Engineering change request (ECR)}

The DFMEA step called "Engineering Change Request ECR" or "Engineering Change Authorized Document" documents the original project and indicates the detailed description of changes to be done in the two circuits layouts. In worldwide companies which are responsible to the global projects development, the "Production Support System" (SAP) is utilized to the management \& control of all ECR's documents, which are linked to a determined project. The first step of work is ended with the pre-project errors analysis, and this analysis is composed by indication, numeration and tabulation of electric circuits design failures. Thus, a "changing frame" is composed through a table, that appoints the modifications to be done in each failure in the next steps of project development. The next Figures show the failures samplings of electrical circuit "G1" and "G2", respectively.

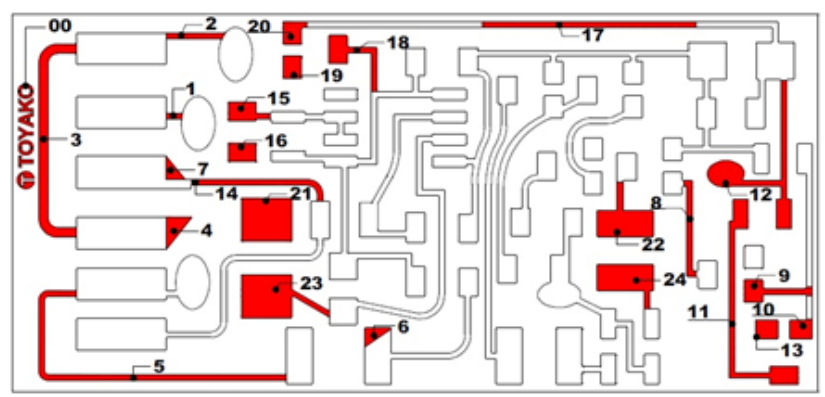

Figure 13. Failures sampling of circuit " $\mathrm{G} 1$ "

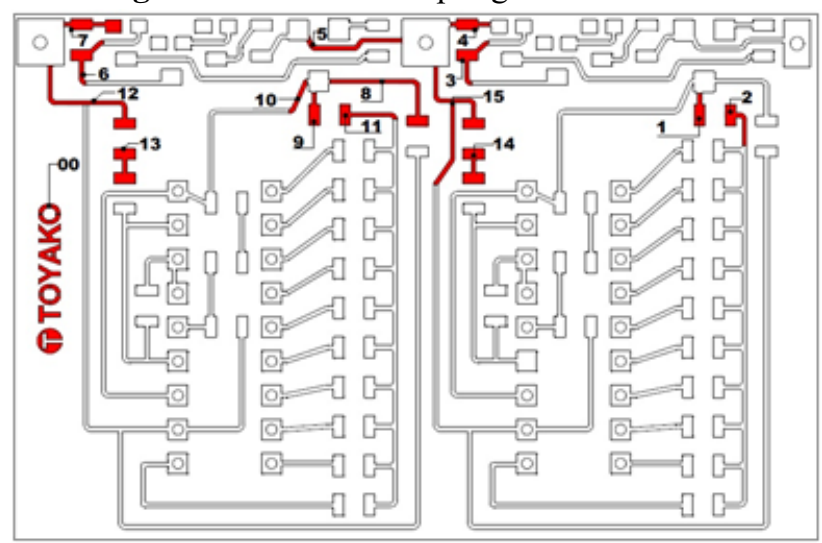

Figure 14. Failures sampling of circuit "G2"

\subsection{Second DFMEA step: Analysis of SMT components integrated in circuits}

After the conclusion of Engineering Change Request (ECR) step, the changes to be done in the electrical circuits "G1" and "G2" must be approved by engineer's team, and this step constitutes the third DFMEA step of DFMEA methodology. This procedure will define the production parts to be employed in the product fabrication. In the case of this work, all the electrical components integrated to the two circuits of analog voltmeter were approved by engineering team after ECR and addressing of SMT components conference. The third DFMEA step is described in the next subtopic of this section.

It's important observe that during this process, there was no components addiction or subtraction from electrical circuits "G1" and "G2", because the changes to be done in that circuits was restricted to voltmeter layers restructuration only. 


\subsubsection{Analysis \& addressing of SMT components}

This step constitutes the failure mode and effect analysis of the developed project. In that DFMEA step, a checklist is created containing all the critical or elevated characteristics of product.

To those critical characteristics can be appointed, it's necessary analyses the SMT components of two electrical circuits, comparing them with the changes to be done in the next development steps. For this, are used the electrical diagrams containing the components addressing, the components list of electrical circuits "G1" and "G2" to be approved by engineer's team, the fails sampling, and the ECR changing frames of each electrical circuit. The Figure 15 and Figure 16 shows the addressing of SMT components.

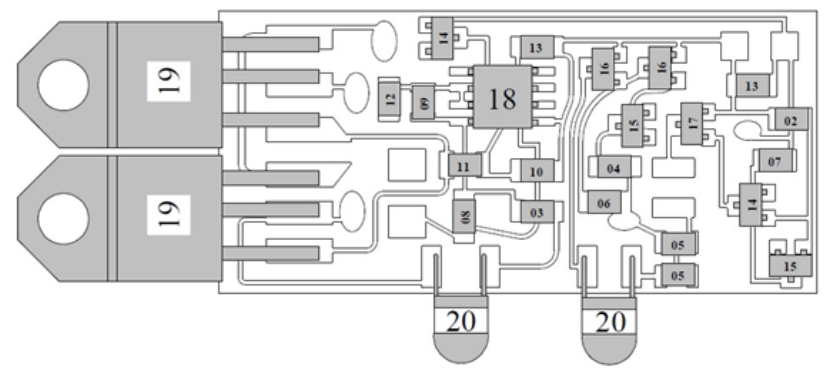

Figure 15. Addressing of circuit "G1"

Table 4. Critical characteristics of circuit "G1"

\begin{tabular}{|c|c|c|c|}
\hline \multicolumn{4}{|c|}{ Electrical circuit $\mathbf{G 1}$ failure mode analysis } \\
\hline Fails & Compr & ents & $\begin{array}{c}\text { Trails and } \\
\text { Pads }\end{array}$ \\
\hline 24 & 2 & & 25 \\
\hline Fail No & SMT code & Severity index & Fail risk \\
\hline 01 & 19 & 1 & Welding \\
\hline 02 & 19 & 1 & Welding \\
\hline 03 & 19 & 2 & Restrict area \\
\hline 04 & 19 & 3 & Noise \\
\hline 05 & 19 and 20 & 2 & Restrict area \\
\hline 06 & 20 & 3 & Noise \\
\hline 07 & 19 & 3 & Noise \\
\hline 08 & 14 and 17 & 1 and 3 & Delay/space \\
\hline 09 & 14 & 1 & Space \\
\hline 10 & 15 & 3 & Noise \\
\hline 11 & $04,06,07$ and 15 & 3 & Delay \\
\hline 12 & 07 & 1 & Space \\
\hline 13 & 15 & 1 & Space \\
\hline 14 & 11 and 19 & 1 & Space \\
\hline 15 & 12 & 1 & Space \\
\hline 16 & 12 & 1 & Space \\
\hline 17 & 14 & 2 & Restrict area \\
\hline 18 & 14 and 18 & 1 & Space \\
\hline 19 & 14 & 1 & Space \\
\hline 20 & 14 & 1 & Space \\
\hline 21 & $\mathrm{~N} / \mathrm{E}$ & 1 & Space \\
\hline 22 & 17 & 1 & Space \\
\hline 23 & 08 & 1 & Space \\
\hline 24 & 05 & 1 & Space \\
\hline
\end{tabular}

2.5. Third DFMEA step: Engineering approbation of ECR documents and SMT components

After conclusion of second DFMEA step, the engineering team must approve and apply the changes recommended by ECR documentation to the electrical circuits "G1" and "G2", otherwise, the fails appointed in Table 4 and Table 5 would implicate significantly the electrical circuits working performance in the areas of Figure 13 and Figure 14. As described in the introduction of previous subtopic, there was no addiction or subtraction of SMT components, because the changes to be done in both circuits were about layers design restructuration to the SMT optimization, and not about components restructuration design. Thus, the production parts definition to be employed in the product fabrication of analog voltmeter, have approved the SMT components described in the Table 15 and Table 16.

As results, we have obtained six final circuits layouts: two restructured circuits, two addressing of SMT components after restructuration and "G1-F" and "G2-F" circuits to etching process.

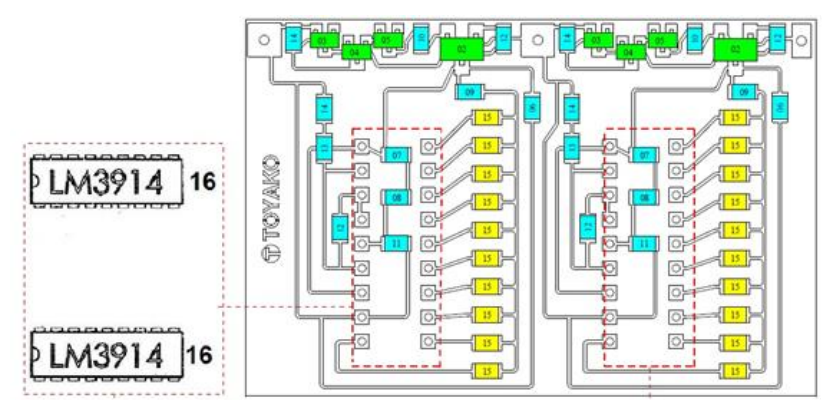

Figure 16. Addressing of circuit "G2"

Table 5. Critical characteristics of circuit "G2"

\begin{tabular}{|c|c|c|c|}
\hline \multicolumn{4}{|c|}{ Electrical circuit G2 failure mode analysis } \\
\hline Fails & \multicolumn{2}{|c|}{ Components } & $\begin{array}{l}\text { Trails and } \\
\text { Pads }\end{array}$ \\
\hline 15 & \multicolumn{2}{|c|}{16} & 55 \\
\hline Fail $\mathbf{N}^{\mathbf{o}}$ & $\begin{array}{l}\text { SMT } \\
\text { code }\end{array}$ & $\begin{array}{c}\text { Severity } \\
\text { index }\end{array}$ & Fail risk \\
\hline 01 & 08 & 1 & Space \\
\hline 02 & 08 & 1 & Space \\
\hline 03 & 02 & 1 & Space \\
\hline 04 & 02 & 1 & Space \\
\hline 05 & 01 & 1 & Space \\
\hline 06 & 02 & 1 & Space \\
\hline 07 & 02 & 6 & $\begin{array}{c}\text { SMT } \\
\text { performance }\end{array}$ \\
\hline 08 & 01 and 05 & 1 & Space \\
\hline 09 & 08 & 1 & Space \\
\hline 10 & 01 and 08 & 1 & Space \\
\hline 11 & 08 & 1 & Space \\
\hline 12 & 03 and 13 & 5 & Space \\
\hline 13 & 12 and 13 & 1 & Space \\
\hline 14 & 12 and 13 & 2 & Space \\
\hline 15 & 13 & 1 & Space \\
\hline
\end{tabular}

\subsubsection{Process flow diagram}

The process flow diagram indicates all the fabrication steps and sequence, including new components. In the case of restructuration of electrical circuits "G1" and "G2", that fabrication sequence is the proper sequence of changing frame developed in the subtopic 2.3.2. 
The word "fabrication" in the context of this current work, refers to the confection and development of electrical circuits in AutoCAD 2010, thus, the restructuration of electrical circuits "G1" and "G2" is the virtual fabrication of product in focus (project DFMEA), in this case the analog voltmeter, which serves a base to the physical fabrication in the production line. Therefore, there is the necessity to distinguish those two context types of "fabrication" term, being used in this work virtually.

\subsubsection{PFMEA}

The PFMEA (Process Failure Mode and Effects Analysis) follow the process flow steps and are indicated the errors that can be occur during product fabrication and in the group of each component. Thus, in the context of analog voltmeter project, the PFMEA step will be employed to assure that changes to be done in the electrical circuits "G1" and "G2" can be realized in a safety mode, avoiding execution errors during the restructuration of analog voltmeter layers.

As the fabrication of project occur in the virtual plan, it's necessary follow all the technical specifications of ECR changing frames (Table 4 and Table 5) to avoid that errors of execution appear during the confection of electrical circuits in AutoCAD, thus, there is no necessity of creating a working procedure to the layers restructuration.

\section{Results}

In the application of this methodology, the percentage of potential failures was about $61 \%$ to the first circuit and $38 \%$ to the second circuit as shown the graphics in the next subtopic at step of quantitative analysis. The results indicates that the application of DFMEA is efficient to reduce potential failures during the project development.

The second subtopic shows the six final circuits obtained after ECR and SMT components approbation by engineer's team, as described in the introduction of subtopic 2.5 of the previous section.

The third subtopic of this section will demonstrate the analog voltmeter functionality tests and battery equalization procedures.

To effect of results comparison, the results exposed in the subtopics 3.2 and 3.3 of this section will be analyzed with the results of work [8], in the section 4. of this paper (Discussion), exposing in this way the main advantages/gains of this current developed work.

\subsection{Quantitative analysis: fail criteria and SMT components}

The graphics 1, 2, 3 and 4 shows the generated results using DFMEA methodology. The results description is cited below:

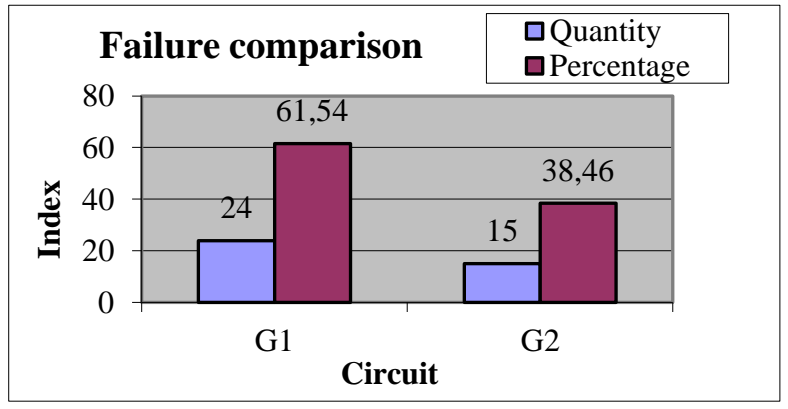

Figure 17. Graphic 1

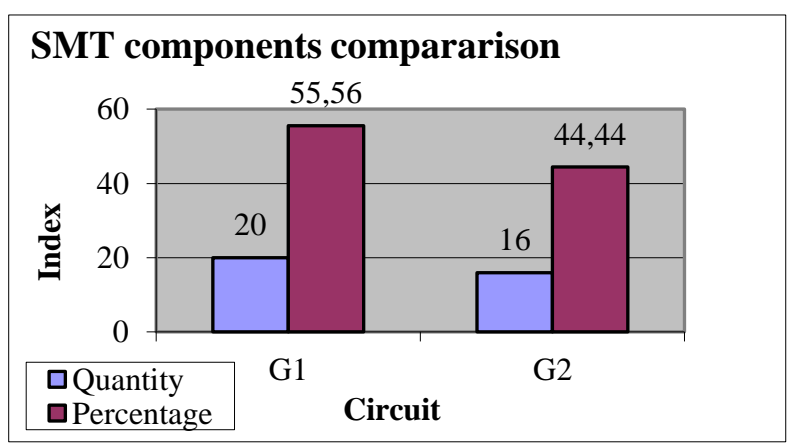

Figure 18. Graphic 2

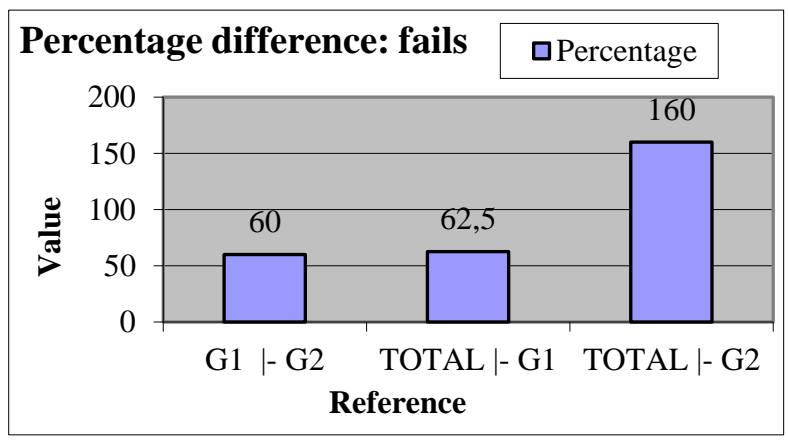

Figure 19. Graphic 3

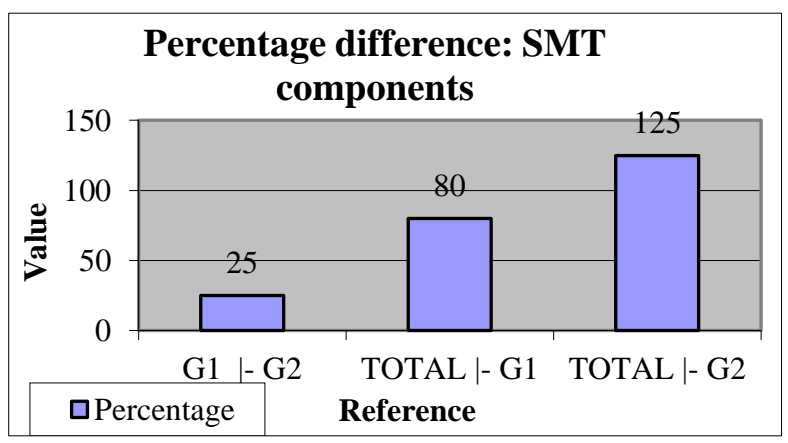

Figure 20. Graphic 4

\subsection{Final circuits layout to etching process}

The final result of DFMEA methodology application is represented by 1 final circuit to electrical circuit "G1" and 1 final circuit to electrical circuit "G2" as described below: 


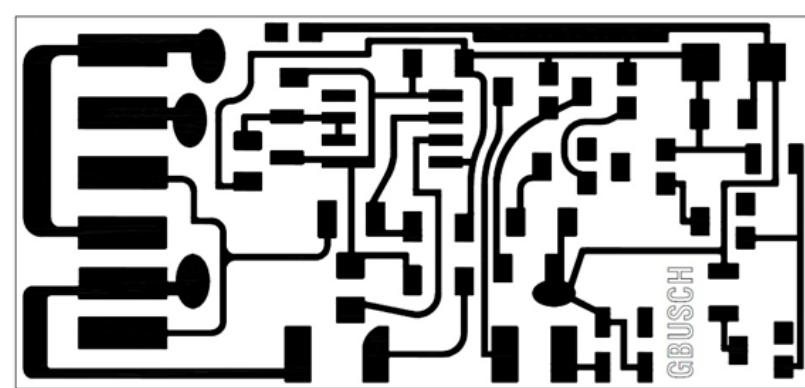

Figure 21. Electrical circuit "G1-F" final diagram to etching process

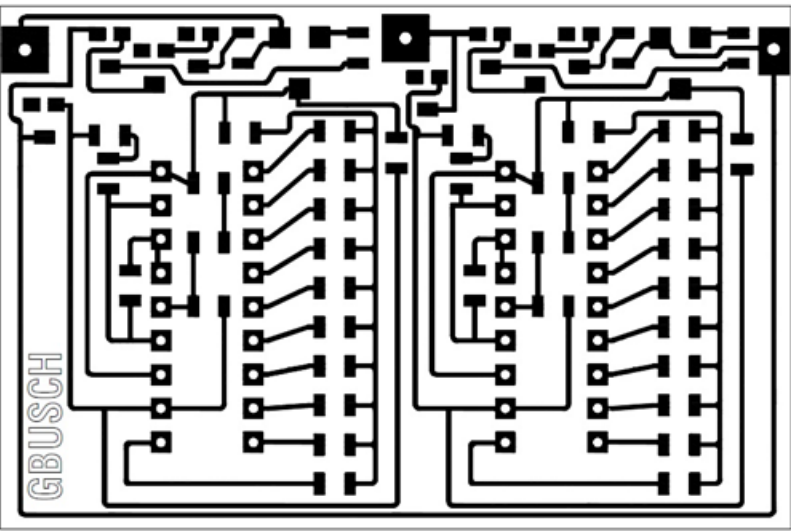

Figure 22. Electrical circuit "G2-F" final diagram to etching process

\subsection{Performance tests of electrical circuits "G1" and "G2"}

The Figure 23 represents the electrical diagram developed in Proteus software desired to make computational tests in circuits.

\subsubsection{Physical tests in the vehicle}

The electrical circuits "G1" and "G2" of analog voltmeter realizes the charges monitoring of batteries, in this mode the equipment do the redirection of the major current part from alternator to the second battery until the equalization between both charges.

Regarding to the analog voltmeter functionality tests, the working principle is on the total loading analysis between 27.8 and $28.0 \mathrm{v}$. After the first battery reaches a loading value of $13.8 \mathrm{v}$ the voltmeter will start to work, managing and loading the two batteries connected in series, until the equalization around $13.9 \mathrm{v}$ for each battery. After this equalization and not having excessive consumption the process is suspended up to a new loading necessity. The next Figure 24 illustrates the process of redirection and charges equalization of two vehicle batteries.

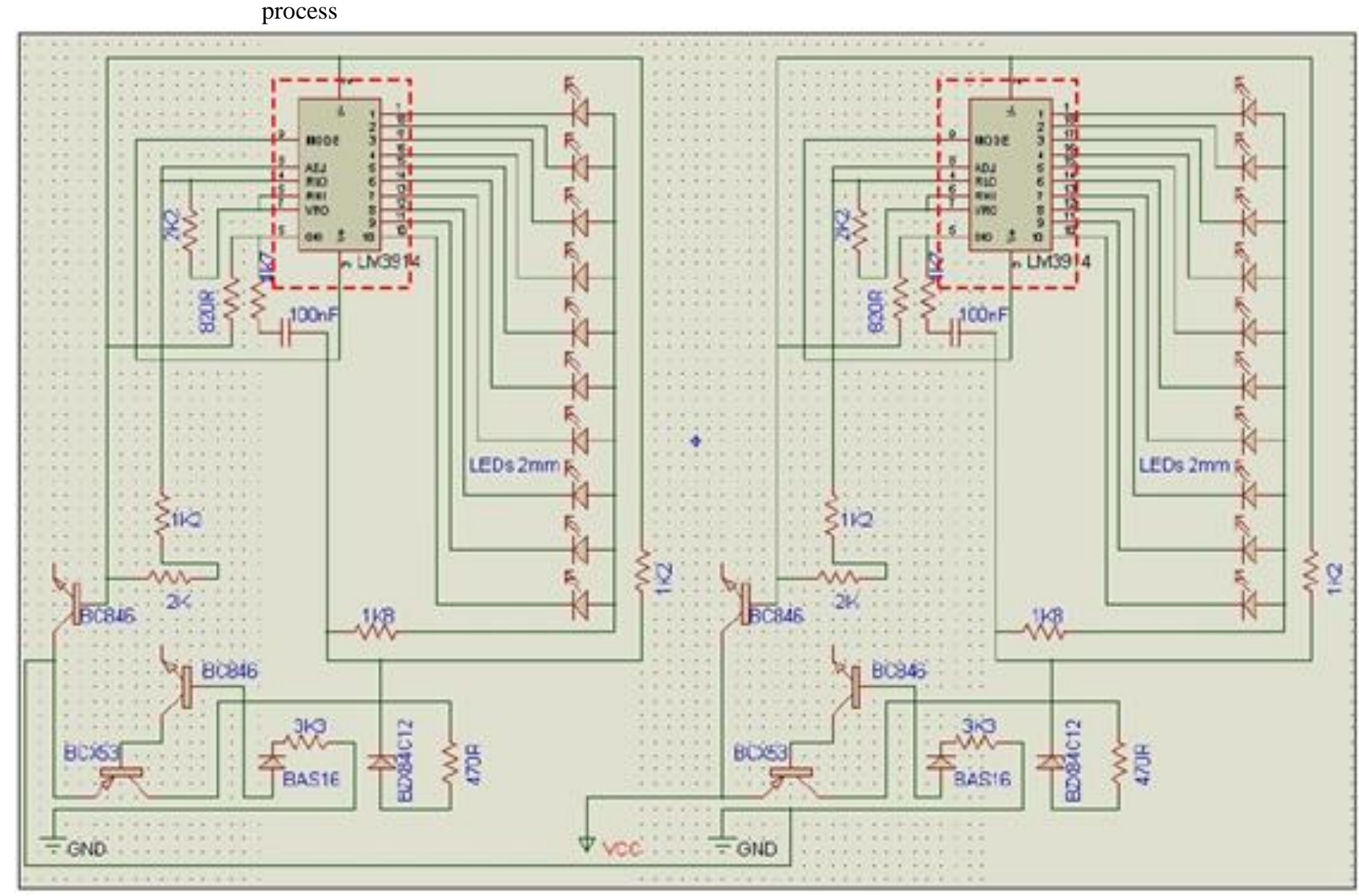

Figure 23. Electrical diagram of circuit "G2" developed in Proteus software

The blue wire (1) will connect the analog voltmeter (2) to the display (3) that must be installed on vehicle panel (4), the display will be connected in $25 \mathrm{v}$ (5) preferably in the general wire (6) that is the positive wire with a lager thickness that is placed down from vehicle panel. Then, we must connect the red wire (7) in the positive set and the black wire (8) in the 
negative (GND). When we turn on the vehicle automatically, the lights of device (9) will bright appointing the charges of battery 1 and battery 2 . It's necessary realize the periodic maintenance of batteries verifying the fluid and the general connections conditions.

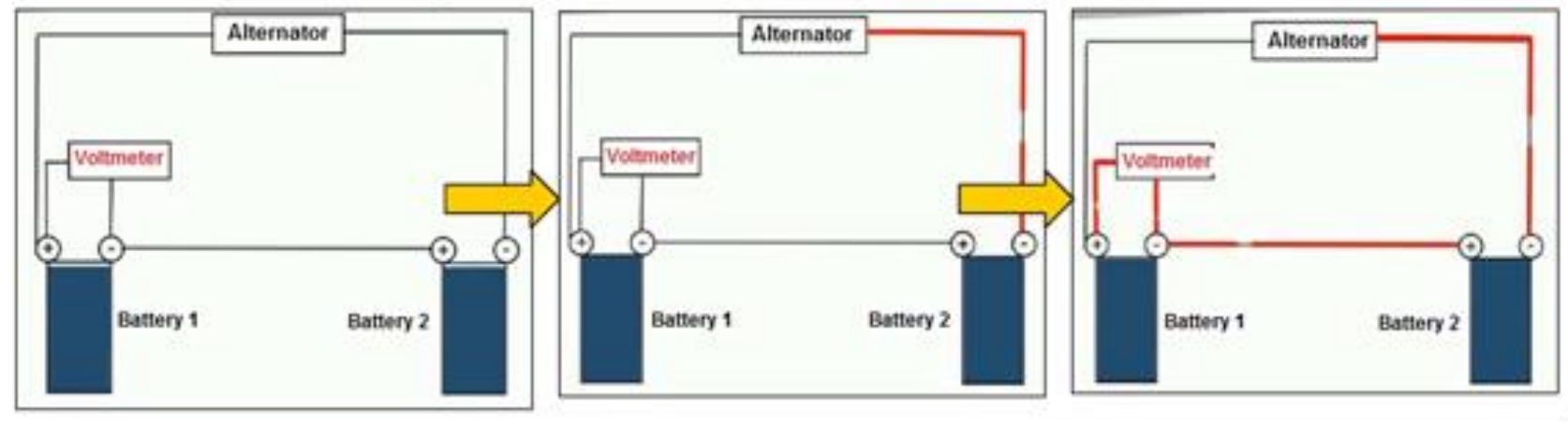

Figure 24. Batteries charge redirection and equalization using analog voltmeter

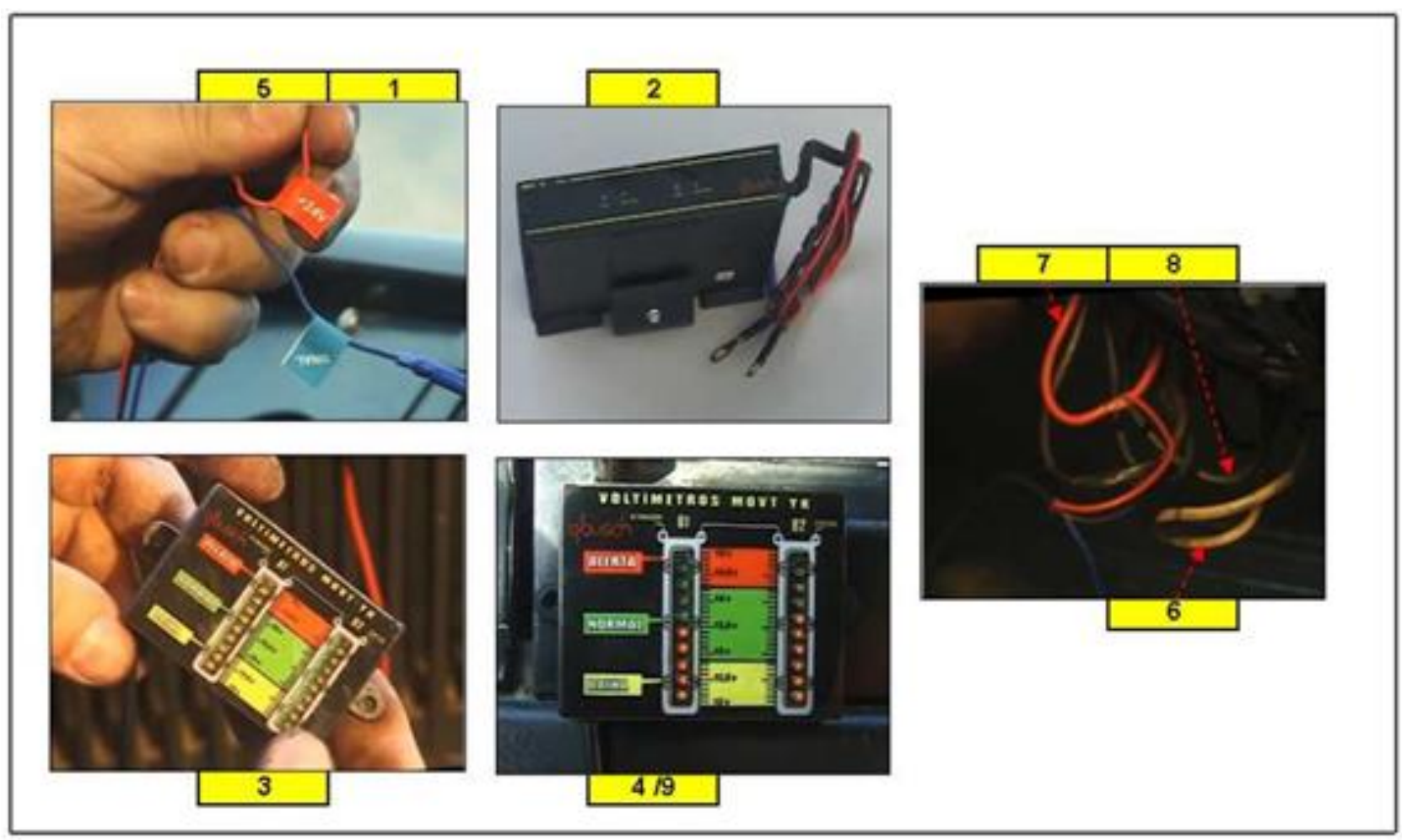

Figure 25. Analog voltmeter performance tests

\section{Discussion}

To effect of results comparison, the results exposed in the subtopics 3.2 and 3.3 of the previous section will be analyzed with the results of work [8], in this section, exposing in this way the main advantages/gains of this current developed work.

\subsection{Results comparison with article "Construction of Microcontroller Based Digital Voltmeter"}

In the Part 4.5 (Results) of article [8], is exposed the final confection of circuit layout design regarding to the digital voltmeter as we can see in the Figure 26 below.

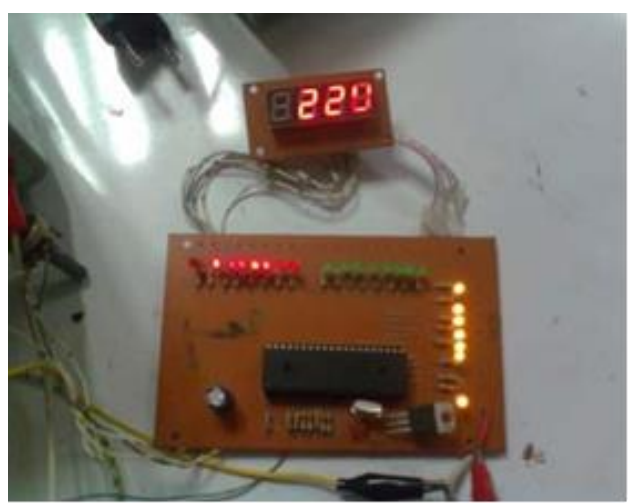

Figure 26. Digital voltmeter 
As we can see in the image above, though this digital voltmeter has the advantage of measure voltage ranges from $0-220 \mathrm{v}$ in the 7 -segment display, there is no application in the batteries charge management of an automotive vehicle, because the components employed in the electrical circuit of digital voltmeter (see section 4.1 of article [8] - Components Used) don't have the analog voltmeter SMT components technology.

Another aspect observed, it's about the size of final products obtained: analog voltmeter and digital voltmeter. In the case of analog voltmeter work, SMT components are used in the electrical circuits which have a huge advantage in relation to the PTH (Pin Through Hole) components in terms of dimension, welding process and layers design optimization. As result of work regarding to the article [8], was obtained a final product which is much larger, in terms of board size than analog voltmeter final product, because of in the work [8] were used PTH components and in the current work were used SMT components.

Therefore, the digital voltmeter of work [8] can't be used in the panel of automotive vehicles. Figure 27 shows the optimized size of analog voltmeter installed on a vehicle panel.

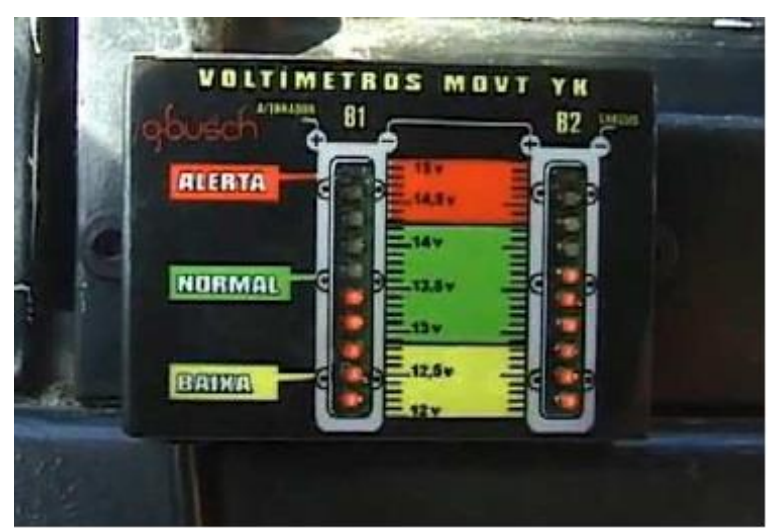

Figure 27. Analog voltmeter installed on panel

\section{Conclusion}

This developed work regarding to the construction of an analog voltmeter, using DFMEA methodology, requires the practical application of concepts about the PCB layout design techniques, electrical circuit analysis, CAD software, measurement and control devices topics, electricity, electronic components analysis and automotive project analysis. All those applications consolidated and integrated the DFMEA methodology with the circuits theory applied in this work, enabling the development of analog voltmeter. About the DFMEA methodology, the main step occurs in the subtopic 2.4.1. (Analysis and addressing of SMT components), step which is the base to the graphic results obtained in the subtopic 3.1. (Quantitative analysis: fail criteria and SMT components), being the percentage of potential failures about $61 \%$ to the first circuit and $38 \%$ to the second circuit. That is explained because of the number of SMT components in the electrical circuits "G1" and "G2": while electrical circuit "G1" has 20 SMT components integrated in the circuit, the electrical circuit "G2" has 16 SMT components in the circuit. Thus, the potential failure probability it's more propose to occur in the first electrical circuit because the major number of SMT components.

From the PCB design layout development of analog voltmeter, it's possible obtain solutions to the automotive vehicle energy management through an electronic embedded system installed on the vehicle's panel.

Thus, to reach the objective of applying the mathematical and physical concepts behind the working principle of analog voltmeter, and assure the great safety and efficiency regarding to the vehicle batteries energy management, was necessary re-design the electrical circuits "G1" and "G2" in AutoCAD following the ECR recommendations. In this mode, was obtained the final layout circuits to etching process with high quality and zero-defect.

\section{Acknowledgment}

I thank God by Always help me reach my objectives.

To my family, by unconditional support demonstrated in all moments during my Master Degree.

To the research team of Laboratory of Communications ( $L C V$ ). To my friends that always be present during my Master Degree. To all professor and employees of School of Electrical and Computer Engineering (FEEC) that has helped me during the development of this work, always ready to give me help.

To all the people that contributed in a directly or indirectly way for that this work would be realized.

\section{References}

[1] F239 - Física Experimental III, "Instrumentos de medida elétrica," Institúto de Física Gleb Wataghin - UNICAMP. [2] D. K. Bonello, "Relatório de Estágio de Curso Técnico de Mecatrônica," Colégio Politécnico Bento Quirino, 2011.

[3] A. Santana and M. Massarani, "Engenharia do valor associada ao DFMEA no desenvolvimento do produto," Society of Automotive Engineers Inc, 2005.

[4] P. Theo and K. Case, "Failure modes and effects analysis through knowledge modelling," Journal of Materials Processing Technology, pp.253-260.

[5] S.H. Teng and S.Y. Ho, "Failure mode and effects analysis," International Journal of Quality \& Reliability Management, vol. 13, pp.8-26, no.5.

[6] FMEA - Third Edition, "Potential failure mode and effects analysis," DaimlerChrysler Corporation, Ford Motor Company, General Motors Corporation, 2001.

[7] FMEA Handbook, "Failure mode and effects analysis - version 4.1," Ford Motor Company, 2004.

[8] Md. Imran Hossain Jony and Md. Moshiur Rahman, "Construction of microcontroller based digital voltmeter," 
International Journal of Science and Research (IJSR), vol. 3, pp.1-4, no.1.

[9] S. Clodoaldo, "Aplicações com o circuito integrado LM3914," Clube da Eletrônica, 2006. Avaliable at: http://www.clubedaeletronica.com.br.

[10] B. Newton C., "Produtos/componentes: código para resistores SMD," Saber Eletrônica, 2008. Avaliable at: http://www.sabereletronica.com.br/secoes/leitura/658.

[11] B. Newton C., "Projetos/manutenção: retrabalho de componentes SMD," Saber Eletrônica, 2008. Avaliable at: www.sabereletronica.com.br/secoes/leitura/1292. 